PONTIFÍCIA UNIVERSIDADE CATÓLICA do RIO dE JANEIRO

\title{
A Preferência dos Consumidores nas Comunicações com Empresas
}

Carolina d'Arcanchy Nóbrega de Souza

Trabalho de Conclusão de Curso

Centro de ciências socials - CCS

DEPARTAMENTO DE AdMINISTRAÇÃo

Graduação em Administração de Empresas 

R I O

Carolina d'Arcanchy Nóbrega de Souza

A Preferência dos Consumidores nas Comunicações com Empresas

Trabalho de Conclusão de Curso

Trabalho de Conclusão de Curso, apresentado ao programa de graduação em Administração da PUC-Rio como requisito parcial para a obtenção do titulo de graduação em Administração.

Orientadora: Marina Frid 


\section{Resumo}

DE SOUZA, Carolina. A Preferência dos Consumidores nas Comunicações com Empresas. Rio de Janeiro, 2017. Número de páginas p. 33. Trabalho de Conclusão de Curso - Departamento de Administração. Pontifícia Universidade Católica do Rio de Janeiro.

O objetivo deste trabalho é entender as preferências dos consumidores brasileiros de idades variadas, nas classes $A$ e $B$, em relação à comunicação com empresas, mantendo como principais focos de estudo: compra de produtos/agendamento de serviços e reclamações/resoluções de problemas.

Foi realizada uma pesquisa de campo exploratória qualitativa no grupo em questão e seus resultados foram analisados sob o embasamento de três principais teorias: teoria dos nativos e imigrantes digitais, cibercultura e convergência digital.

As principais conclusões foram: (1) a idade, surpreendentemente não influenciou nas preferências, (2) todo o grupo prefere iniciar comunicações com empresas via internet através de sistemas de mensagens síncronas e receber comunicações de empresas via internet através de sistemas de mensagens assíncronas, e (3) apenas no caso de emergências ou necessidades imediatas apareceu a preferência pelo canal telefônico.

\section{Palavras- chave}

Comunicação Consumidor Empresa, Cibercultura, Convergência Digital, Nativos Digitais, Imigrantes Digitais 


\section{Abstract}

DE SOUZA, Carolina. Consumer Preferences When Communicating with Businesses. Rio de Janeiro, 2017. Número de páginas p. 33. Trabalho de Conclusão de Curso - Departamento de Administração. Pontifícia Universidade Católica do Rio de Janeiro.

The purpose of this study is to understand the preferences of Brazilian consumers, of different ages and within the $A$ and $B$ social classes, in relation to their communication with businesses, having as the primary focus of study: the purchase of products or scheduling of services and complaint or resolution of problems.

An exploratory-qualitative field research was done in order to investigate the premises with the group described above. The results were analysed under the following three theories: Digital Natives and Digital Immigrants, Cyberculture and Digital Convergence.

The main conclusions were: (1) age difference was not identified as a factor influencing their preferences, (2) unanimously, the group preferred starting communications with businesses via the internet through synchronous message systems while at the same time, preferred businesses to communicate with them using asynchronous message systems, and (3) only in the case of emergencies or immediate necessity were consumers prepared to call the businesses.

\section{Key-words}

Communication Consumer Business, Cyberculture, Digital Convergence, Digital Natives, Digital Immigrants 


\section{Sumário}

1 O tema e o problema de estudo 1

1.1. Introdução ao tema e ao problema do estudo 1

1.2. Objetivo do estudo 2

1.3. Objetivos intermediários do estudo 2

1.4. Delimitação e foco do estudo 3

1.5. Justificativa e relevância do estudo 4

2 Revisão Teórica $\quad 5$

2.1. Teoria dos Nativos e Imigrantes Digitais 5

2.2. Cibercultura ou Sociedade em Rede 6

2.3. A Cibercultura e a Perspectiva Antropológica 7

$\begin{array}{ll}\text { 2.4. Convergência Digital } & 10\end{array}$

3 Métodos e procedimentos de coleta e de análise de dados do estudo 12

3.1. Etapas de coleta de dados 12

3.2. Fontes de informação selecionadas para coleta de dados no estudo13

3.3. Procedimentos e instrumentos de coleta de dados utilizados no $\begin{array}{ll}\text { estudo } & 15\end{array}$

3.4. Formas de tratamento e análise dos dados coletados para o estudo 16

3.5. Limitações do Estudo

4 Apresentação e análise dos resultados

4.1. Unanimidade em relação à preferência por serviços de mensagem para comunicação com empresas

4.2. Preferências entre serviços de mensagens síncronos ou assíncronos em função do tipo de comunicação com as empresas 19

4.3. Vantagens percebidas no agendamento de serviços via internet 21

4.4. Acreditam que a comunicação telefônica é falha 22

4.5. Acreditam na necessidade de um canal telefônico para solução mais imediata de problemas com empresas 
4.6. Acreditam que a comunicação com empresas por e-mail não seja imediata ou garantida o suficiente

5 Conclusões, Sugestões e Recomendações

6 Referências Bibliográficas

Anexo 1 - Roteiro Semi-Estruturado das Entrevistas

Anexo 2 - Quadro de Meios de Comunicação 


\section{0 tema e o problema de estudo}

\subsection{Introdução ao tema e ao problema do estudo}

De acordo com a pesquisa "Mensageria no Brasil", feita em fevereiro de $2017,92,1 \%$ dos internautas brasileiros possuem smartphone. Smartphone este que é caracterizado por ser um celular que possui tela sensível ao toque e que permite ao usuário instalar e desinstalar aplicativos livremente. Destes internautas que possuem um smartphone, 98,1\% deles tem o aplicativo WhatsApp instalado. Ou seja, o WhatsApp está para os smartphones no Brasil da mesma forma que a TV Globo está para os televisores: é praticamente onipresente.

Ainda segundo à pesquisa mencionada, o WhatsApp é onde $69,1 \%$ dos internautas usuários de smartphones passam mais tempo por dia dentro dos meios de comunicação. Outro ponto interessante de citar é quando os usuários foram questionados sobre seu interesse em conversar com empresas por aplicativos de mensagens como WhatsApp, Facebook Messenger e Telegram, os usuários responderam que sim em 76,3\%,60,3\% e 67,6\%, respectivamente.

Aos nossos olhos de cidadãos adultos do século XXI, a evolução tecnológica da interação via telefone para a interação via internet, tanto nas relações pessoais, quanto comerciais, parece natural, sejam estas relações consumidor com empresa ou vice-versa. Realmente, segundo Lévy (1999, p. 49), "A comunicação continua, com o digital, um movimento de virtualização iniciado há muito tempo pelas técnicas mais antigas, como a escrita, a gravação de som e imagem, o rádio, a televisão e o telefone."

Neste momento, a conveniência proporcionada pelo acesso à internet para interagir com pessoas e empresas se tornou esperada. Não se espera que uma pessoa não pertença a pelo menos um canal de comunicação de mídia social. Assim como não se espera que empresas não tenham alguma forma de presença digital, seja um site próprio, uma página de Facebook, um perfil no Google MyBusiness ou a presença no LinkedIn.

Já a geração Z, os considerados "Nativos Digitais" (Prensky, 2001), não conhecem o mundo sem a internet. Portanto, parece natural que, grande parte da interação desta geração com pessoas ou empresas seja, via a internet, 
utilizando meios de comunicação tipicamente impessoais (como podemos ver na tabela no Anexo 2). Esta impessoalidade se dá porque todas essas relações ganharam versões equivalentes online, sem contato humano direto. Ou seja, pesquisar informações, fazer compras, recomendações, reclamações, se conectar com amigos, realizar formações profissionais são exemplos de relações que ficaram mais comuns online.

Analogamente, podemos observar este efeito presente nas relações comerciais desta geração. Eles interagem entre si de uma forma impessoal, utilizando aplicativos e mídias sociais para se comunicarem uns com os outros. Suas relações comerciais, naturalmente, obedecem ao mesmo padrão: impessoal e via internet.

Mas, mesmo os não nativos digitais já se acostumaram com a conveniência da utilização da internet na comunicação interpessoal e na busca por empresas, produtos e serviços. A análise deste trabalho sugere que consumidores de diferentes faixas etárias estão interagindo com empresas sempre que possível, via internet, de uma forma mais imediata, impessoal e muitas vezes assíncrona.

\subsection{Objetivo do estudo}

Portanto, este estudo pretende analisar a preferência dos consumidores brasileiros da cidade do Rio de Janeiro, de idades variadas, nas classes A e B, com acesso a uso de eletrônicos e Internet.

O objetivo foi entender as preferências entre a comunicação online através de e-mail, chat, mídias sociais - e a comunicação telefônica (representando a comunicação direta) na interação com empresas. E a partir disso, sugerir adequações nos canais de comunicação entre empresas e consumidores.

\subsection{Objetivos intermediários do estudo}

Para atingir o objetivo final proposto, este estudo pretende alcançar os seguintes objetivos intermediários: 
$\checkmark$ Identificar causas que podem influenciar na mudança do comportamento de comunicação dos consumidores com empresas.

$\checkmark$ Entender melhor os novos consumidores, como interagem com as empresas das quais consomem serviços e/ou produtos, e a mudança (ou não) no comportamento dos antigos.

$\checkmark$ Analisar fatores que podem influenciar a inibição de utilizar o telefone (fixo e/ou celular) para fazer ligações. O propósito desta análise é verificar se os métodos mais comuns de interação com uma empresa ou instituição mudaram.

\subsection{Delimitação e foco do estudo}

Este estudo volta-se mais especificamente para abordar a questão da mudança na preferência dos consumidores de nível sócio cultural alto e destreza no uso da internet em relação a como interagir e se comunicar com empresas e instituições. É natural que aconteça esta mudança com o desenvolvimento de novas tecnologias, porém, neste caso, ainda utilizamos uma evolução da mesma ferramenta: o telefone, que se tornou celular e que, por sua vez, se transformou no smartphone.

O telefone smartphone, hoje em dia, é utilizado pelas mais diversas razões, dentre elas, a ligação telefônica. O propósito do celular foi mudando ao longo dos anos com a evolução de suas funcionalidades e novas tecnologias podem tomar o lugar das antigas. Este estudo tem como foco entender as motivações por trás das preferências dos consumidores, a preferência dos consumidores quando vão se comunicar com empresas e verificar a mudança para tecnologias impessoais e assíncronas.

Com este objetivo, o estudo pretende analisar dois tipos de interação com empresas: como compram um produto ou agendam um serviço e como reclamam ou resolvem um problema. Pretendo analisar como cada pessoa da pesquisa se comunica com empresas principalmente nestes tipos de interação. Desta forma, poderemos observar interações relativas ao pré compra, durante e pós compra de produtos ou serviços.

Um dos focos é verificar se a idade do consumidor é um fator diferenciador na escolha na forma como vão interagir com empresas. Se a idade realmente for um diferenciador isto poderia indicar uma tendência de jovens não utilizarem 
mais o celular para fazerem ligações e, neste caso, as empresas terão que entender esta mudança de comportamento e segui-la para acompanhá-los.

É importante lembrar que este estudo não pretende ser amplo no que diz respeito a classe social ou região geográfica, isto exigiria um período maior de pesquisa e amostragem definida com base estatística para ter validade.

\subsection{Justificativa e relevância do estudo}

O estudo vai buscar entender a mudança de comportamento dos consumidores na interação com empresas. O tema é relevante no mercado atual onde as empresas têm que se adaptar para conseguirem se comunicar e aumentar aproximação com seus clientes.

Empresas de qualquer setor do mercado se beneficiariam com este estudo, porque mostrará a elas a importância da compreensão dos novos comportamentos de consumidores da nova geração e como adaptarem seus canais de comunicação com o mercado para atender às novas exigências.

Os resultados a serem alcançados com este estudo serão interessantes, principalmente, para empresas que funcionam com agendamento de serviços, como cabeleireiros e clínicas médicas, por exemplo. Estas empresas podem estar anunciando seus serviços na internet, porém somente utilizando seu telefone como canal de agendamento. Este talvez não seja o melhor canal, se seus usuários preferirem agendamento online.

Mesmo para as empresas que já fazem altos investimentos no meio digital, acredito que um estudo que entende os diversos canais e como interagir com cada um deles é muito interessante. Olhando os resultados de meu estudo e as reais presenças de marcas na web, vejo muitas inconsistências. Ainda enxergam esse meio, por exemplo, mais como local de vendas que de agendamento ou solução de problemas. E como propaganda - no sentido de propagar conceitos - que de relacionamento com o consumidor.

Além das empresas mencionadas acima, as informações que este estudo pretende produzir podem se mostrar de interesse também para os consumidores, se suas preferências na comunicação com empresas forem realmente implementadas. 


\section{Revisão Teórica}

\subsection{Teoria dos Nativos e Imigrantes Digitais}

Marc Prensky (2001) cunhou os termos "nativos digitais" e "imigrantes digitais" para descrever dois grupos de pessoas no século XXI. O artigo escrito pelo autor compara estudantes nascidos na era digital ("nativos digitais") e aqueles nascidos antes ("imigrantes digitais"). Uma das conclusões do artigo foi de que os estudantes não são mais os mesmos, estes aprendem e se comportam de maneira diferente de seus professores. Não foi uma mudança apenas de gírias, jeito de se vestir, como aconteceu com as gerações anteriores. Aconteceu uma chamada 'singularidade' - um evento que muda algo fundamental, que não há volta. A 'singularidade' foi a chegada e a rapidez da disseminação da tecnologia digital na última década do século XX.

Os estudantes nascidos a partir do ano 2001 foram a primeira geração que, desde o ensino fundamental até a faculdade, cresceram com esta nova tecnologia. Eles passaram a vida inteira rodeados de computadores, videogames, tocadores de música digitais, câmeras de vídeo, celulares e todas as outras ferramentas e brinquedos que surgiram nesta era digital.

Hoje em dia, é possível ver a quase onipresença da internet e o volume de interação que surgiu com este movimento. Os estudantes pensam e processam informações de um jeito fundamentalmente diferente dos seus predecessores. É muito possível que o cérebro destes novos estudantes tenha mudado fisicamente e sejam diferentes das outras gerações, como resultado de como cresceram. Mesmo que isto não seja verdade, seus padrões de pensamento certamente mudaram.

Assim como também mudaram, em maior ou menor grau, os modelos mentais de todos aqueles que possuem um mínimo de intimidade e destreza no uso de ferramentas digitais: a senhora de 75 que joga paciência ou faz Skype com o filho que mora no exterior no Ipad, o artesão do interior de Minas Gerais que tem seus artigos num portal da web, a meia idade que viaja marcando seu hotel em sites como o Booking.

Prensky chama estes novos estudantes de "nativos digitais" porque eles são "native speakers" da língua digital. Os "imigrantes digitais" são os que 
conseguem aprender esta nova língua, porém ainda retém um "sotaque", pois não é sua língua nativa. Os imigrantes aprenderam a se socializar de uma maneira diferente e aprenderam uma língua nova, e uma língua nova aprendida mais tarde na vida vai para uma parte diferente do cérebro. Podemos perceber esse "sotaque" em várias situações, por exemplo, quando o consumidor que é imigrante digital vai para a internet procurar o telefone de uma empresa direto sem verificar antes se conseguem falar com a empresa online. Ou quando lançam um aplicativo novo e a criança que acabou de entrar nele consegue mexer em tudo e o adulto demora para entender e aprender. São coisas pequenas, mas que no geral acabam fazendo uma diferença grande em como as pessoas pensam, raciocinam e se comportam.

A grande questão que o artigo de Prensky (2001) traz é que professores, que são "imigrantes digitais" e falam uma língua diferente (antes da era digital), estão tendo dificuldade de ensinar uma população que fala uma linguagem inteiramente nova. A principal conclusão é de que os professores e os métodos de ensino têm que se adaptar aos novos alunos nativos digitais.

Isto nos leva a questionar se, analogamente ao ensino (tema do artigo de Prensky), empresas que hoje são lideradas por "imigrantes digitais" não teriam que criar novas formas de interação adaptadas a seus novos consumidores, que são "nativos digitais", se fundamentalmente estes pensam e se comportam de maneira diferente.

\subsection{Cibercultura ou Sociedade em Rede}

Para podermos falar deste tema devemos primeiro definir o que é a cibercultura e o universo no qual ela se encontra, o ciberespaço. Segundo Lévy (1999, p.17), o ciberespaço é:

\footnotetext{
“(...) o novo meio de comunicação que surge da interconexão mundial dos computadores. O termo especifica não apenas a infra-estrutura material da comunicação digital, mas também o universo oceânico de informações que ela abriga, assim como os seres humanos que navegam e se alimentam nesse universo. Quanto ao neologismo "cibercultura", especifica aqui o conjunto de técnicas (materiais e intelectuais), de práticas, de atitudes, de modos de pensamento e de valores que se desenvolvem juntamente com o crescimento do ciberespaço."
} 
A cibercultura está no centro dos estudos sociais sobre a Internet desde os anos 1990, quando teóricos começaram a assumir que um novo modelo cultural iria emergir pelo uso da Internet e que este novo modelo iria mudar os padrões de relações sociais, identidade pessoal e comunidade. A internet foi vista como uma nova tecnologia que iria afetar todos os aspectos de nossas vidas.

Manuel Castells (1999) define essa nova ordem como "Sociedade em Rede", enquanto Pierre Lévy (1999) e Arturo Escobar (2000) a definem como "Cibercultura". Para eles, as pessoas, sociedades e países que não participassem dessa revolução tecnológica seriam excluídos do progresso. Esta nova divisão digital foi vista como a nova definição de divisão social, mais importante do que rico ou pobre, ou países desenvolvidos ou subdesenvolvidos.

A cibercultura, entendida como uma cultura que nasceu do uso generalizado da internet (Porter, 1996), foca na interação social que acontece nos contextos sociais online, como fóruns e chats. $O$ importante não é a tecnologia em si, mas sim a interação social que ocorre no ciberespaço.

Porter (1996) também explica que a comunicação através da Internet pode ser entendida pela perspectiva de cultura, já que em espaços virtuais os participantes podem ter um sistema coletivo de crenças, valores, normas, jeitos específicos de agir, um entendimento comum de símbolos, como os emoticons, uma etiqueta ("netiquette") de Internet, e outros sinais que podem coletivamente ter um senso de pertencimento e criar uma comunidade no ciberespaço.

Reid (1994) fala que, com todas essas interações e criações de normas e regras, podemos perceber um senso de comunidade e pertencimento com características similares às da vida social offline, indicando também uma característica 'cultural' de uma comunidade. Com os trabalhos de Miller e Slater (2000), conseguimos quebrar as dicotomias de online/offline e real/virtual, o que foi muito importante para começarmos a entender que esta interação online já faz parte das atividades diárias de uma pessoa, como uma prática social legítima.

\subsection{A Cibercultura e a Perspectiva Antropológica}

As teorias investigadas nos diversos momentos se baseavam na alta penetração da internet na sociedade. Uma questão interessante no Brasil, é como justificar a alta adoção da cibercultura, mesmo entre as diferentes faixas etárias, a despeito da discrepância social e do percentual da população em situação de pobreza. 
Neste caso, a antropologia pareceu um caminho importante para complementar o âmbito teórico deste trabalho, pois explica a nossa sociedade relacional, como a denomina Roberto DaMatta (1997). Ou seja, como valor cultural, e por diversas razões históricas e de formação da sociedade, o brasileiro busca, mais que outros povos, relacionamentos.

No livro "Carnavais Malandros e Heróis", DaMatta (1997) correlaciona uma ambiguidade vivida pelos brasileiros entre o indivíduo interno (casa) e o externo (rua) numa sociedade altamente hierarquizada que nos leva a este "jeitinho brasileiro", que podemos também codificar como o indivíduo que mesmo no espaço externo à sua casa, é capaz de estabelecer relações e criar situações novas a partir seja de limites ou oportunidades.

Não se trata aqui de julgar este comportamento, mas absorver a teoria de DaMatta para entender que o acesso ao smartphone é, de alguma forma natural, uma maneira de continuidade digital do jeito relacional no mundo off-line.

DaMatta (1997) criou a teoria do triângulo ritual onde distribui os ritos da ordem, da desordem e os cerimoniais neutros das religiões nos espaços da casa, rua e outro mundo. Ainda, segundo o autor:

“(...) a explicação está uma sociedade mestre em transições equilibradas e em conciliações, que estabeleceu para si essa lógica relacional, cuja principal característica é a capacidade de inventar pontes e formas de passagens entre esses espaços estabelecendo as relações. Como esses espaços são segregados e afastados uns dos outros, as festas são momentos importantes para a sociedade brasileira, pois por meio delas se pode relacionar os espaços reunindo-os para a vivência da totalidade. " (DaMatta, 1997, p. 21.)

O Carnaval, por exemplo, é um momento ritual onde se cria esse relacional de forma muito abrangente, onde ordem e desordem não só se misturam, mas se complementam. Também de acordo com Lídia Loureiro da Silva (2004), corrobora os conceitos citados, e fala da internet como base para a reconstrução de identidades e laços sociais:

"A Internet é simultaneamente real e virtual (representacional), informação e contexto de interacção, espaço (site) e tempo, mas que altera as próprias coordenadas espacio-temporais a que estamos habituados, compactandoas, ou seja, o espaço e o tempo na rede existem na medida em que são 
construção social partilhada. Esta construção é estruturada pelos laços e valores socio-políticos, estéticos e éticos que tipificam este novo espaço antropológico. Este novo espaço com áreas de privacidade - um novo mundo virtual ou mundo mediatizado - é um suporte aos processos cognitivos, sociais e afectivos, os quais efectuam a transmutação da rede de tecnologia electrónica e telecomunicações em espaço social povoado por seres que (re) constroem as suas identidades e os seus laços sociais nesse novo contexto comunicacional. " (SILVA, 2004, p. 151)

Então, se temos uma sociedade relacional, como propõe DaMatta, já deveria existir de parte das grandes organizações esta visão estratégica da presença online. A partir das leituras, poderia se dizer que o ciberespaço é o "local" onde praticamos nossa cultura relacional e mesmo nossa cidadania: é nele que nos relacionamos com amigos, empresas, usamos serviços bancários ou mesmo públicos, considerando interações em sites como, por exemplo, Prefeitura ou Detran.

O uso da Internet no Brasil, se comparado a outros países, consegue alinhavar as diferentes teorias e conhecimentos deste capítulo, mostrando que, a despeito dos milhões de brasileiros em situação de pobreza, as crianças brasileiras já seguem padrões de tendências mundiais. Esta é a conclusão do estudo "Children and Internet use: A comparative analysis of Brazil and seven European countries" (2015), desenvolvido pela EU KidsOnline:

"O Brasil tem uma população de mais de 200 milhões de pessoas. Em qualquer discussão sobre o relacionamento de crianças com a mídia e dispositivos móveis, deve ser considerada a vasta diversidade socioeconômica, regional e cultural do país. Enquanto ainda há um grande desafio ao enfrentar a divisão digital, crianças brasileiras seguem a tendência global de crescer dentro de um ambiente saturado pela mídia, que é resultante da crescente presença de dispositivos móveis." (tradução nossa) 


\subsection{Convergência Digital}

Pool (1983) foi o primeiro a traçar o conceito de convergência como um poder de transformação dentro das indústrias midiáticas. Segundo o autor:

"Um processo chamado "convergência de modos" está tornando imprecisas as fronteiras entre os meios de comunicação, mesmo entre as comunicações ponto a ponto, tais como o correio, o telefone e o telégrafo, e as comunicações de massa, como a imprensa, o rádio, a televisão. Um único meio físico - sejam fios, cabos ou ondas - pode transportar serviços que no passado era oferecido separadamente. De modo inverso, um serviço que era oferecido por um único meio - seja a radiodifusão, a imprensa ou a telefonia - agora pode ser oferecido de várias formas físicas diferentes. Assim, a relação um a um que existia entre um meio de comunicação e seu uso está se corroendo. " (POOL, 1983, p. 23)

Pool (1983) compreende que convergência e divergência são dois lados do mesmo fenômeno. Ele explica: "Houve uma época em que empresas publicavam jornais, revistas e livros e não faziam muito mais do que isso; seu envolvimento com outros meios de comunicação era insignificante". Isto é, cada meio de comunicação tinha sua função, uma distinta da outra, o que não é mais o caso.

Henry Jenkins (2009), um autor mais recente, acrescenta que hoje as pessoas falam em divergência ao invés de convergência. Por exemplo, um serviço de mensagens assíncronas, como era o telegrama que só utilizava o telégrafo como meio, hoje está 'divergindo' em diversas formas físicas diferentes: Skype, Messenger, Whatsapp, Telegram, etc.

Para este estudo, é essencial entender a importância de serviços de mensagens assíncronos e síncronos, e a diferença entre os meios de comunicação. Adler e Elmhorst (2010) resumiram em um quadro no Anexo 2. Podemos ver na tabela sua caracterização destes meios de comunicação de acordo com velocidade da resposta e tom da conversa.

Nota-se aqui que, entre 1983 e 2009 - datas de publicação das obras em referência - a tecnologia mudou substancialmente criando o conceito de sociedade da informação, portanto Jenkins (2009) permite-se um ponto de vista de onde já enxerga concretamente o mundo multimídia, com suas ferramentas. 
Um bom exemplo deste pensamento no Brasil seria a TV Globo, que sempre focou em TV aberta e atualmente se faz presente em canais digitais, como o GShow, com spinoffs da programação ou ações complementares às que acontecem na tela analógica. E já lança programas previamente em sua plataforma para assinantes, GloboPlay, onde se pode assistir a qualquer momento o que foi ao ar na TV aberta. Também está presente em todas as redes sociais, com teasers e vinhetas da programação diária, que complementam as chamadas na TV aberta.

Podemos dizer que, ao mesmo tempo, este exemplo concreto fala da convergência de Pool (1983), na medida em que um mesmo ambiente tecnológico se abre como um prisma de possibilidades para o espectador. Mas também fala da divergência a que se refere Jenkins (2009), na medida em que a programação da TV aberta - com hora e dia marcados - se multiplica através de canais digitais. Assim como serviços de mensagem se multiplicam em WhatsApp, Telegram, SMS etc.

O conceito convergência/divergência digital é, portanto, uma moeda de duas faces que pode convergir para uma só. De acordo com o artigo "Conectar físico e digital é mais importante que nunca": "Apesar das evidências de que os consumidores desejam experiências personalizadas, muitas empresas ainda trabalham com uma visão online e outra off-line. " (Navarro, 2017) 


\section{Métodos e procedimentos de coleta e de análise de dados do estudo}

Este capítulo pretende informar sobre as diversas decisões a cerca da forma como este estudo foi realizado.

Suas cinco seções descrevem, respectivamente, as etapas de coleta de dados do estudo realizado e as fontes selecionadas para coleta de informações neste estudo. Na sequência, informa-se sobre os processos e instrumentos de coleta de dados realizados em cada etapa, com respectivas justificativas, sobre as formas escolhidas para tratar e analisar os dados coletados e, por fim, sobre as possíveis repercussões que as decisões sobre como realizar o estudo impuseram aos resultados assim obtidos.

\subsection{Etapas de coleta de dados}

Para este trabalho, foram realizadas duas etapas de coleta de dados, uma bibliográfica e a outra pesquisa de campo exploratória. A pesquisa bibliográfica foi feita antes da pesquisa exploratória para que pudesse ter uma ideia de como formular o questionário.

A pesquisa exploratória foi escolhida para compreender melhor o campo de estudo. Já que existem poucos ou nenhum teórico abordando este tema diretamente - especialmente em relação ao mercado brasileiro - o importante era conseguir respostas da maneira mais ampla possível. Foram usadas entrevistas não padronizadas para poder fazer uma investigação com menor rigidez e esperando assim, respostas mais abertas.

Depois das entrevistas exploratórias, voltou-se à internet para entender melhor os resultados obtidos. Neste momento, intensifou-se a busca de artigos e matérias de revistas que mostrassem a prática das empresas, citadas ao longo do trabalho.

Por último, foram analisadas as informações das entrevistas e da pesquisa de dados secundários, o que permitiu chegar à conclusão desejada: descobrir a preferência dos consumidores entrevistados em relação à comunicação com empresas e seus motivos. 
Foi escolhida a realização da pesquisa exploratória e a pesquisa bibliográfica porque, desta maneira, pode-se ter uma noção melhor do tema abordado. Uma pesquisa apoia e dá suporte para a outra.

\subsection{Fontes de informação selecionadas para coleta de dados no estudo}

A pesquisa foi dividida em duas etapas. A primeira etapa, em busca de dados secundários, foi bibliográfica. Nela foram pesquisados vários autores e temas relevantes ao estudo e com isso pode-se formular o questionário para as entrevistas na segunda etapa, que consistiu em entrevistas exploratóriaqualitativas, onde podem ser coletatados dados primários a fim de complementar o estudo e alcançar os objetivos estabelecidos.

A etapa de coleta de dados por meio de dados secundários foi efetuada pesquisando online por artigos e autores que falassem do assunto de comportamento do consumidor e temas que falassem sobre a mudança que as pessoas e consumidores passaram com a chegada da internet e meios de comunicação mais eficazes e imediatos.

Claro que seria natural buscar as fontes de referência ligadas ao tema digital e tecnologia, mas não se ateve a esta lógica. Também foi feita referência às perspectivas da antropologia, psicologia e do comportamento do consumidor para intercalar diversos conhecimentos.

Ampliar a busca trouxe maior maturidade para definir o roteiro de pesquisa e a análise das falas dos entrevistados. No que diz respeito ao perfil psicológico de consumo dos e-consumers - por exemplo - há inúmeros fatores que contribuem para o sucesso do e-commerce além da boa imagem da empresa, organização, inovação, segurança, qualidade, entre outros. Estes temas foram incluídos na abordagem. Foram realizadas pesquisas mais detalhadas sobre autores que falam sobre estes tópicos, tais como Manuel Castells e Pierre Lévy e Roberto DaMatta.

Já a coleta por meio de dados primários teve como objetivo entrevistar pessoas de idades variadas, moradoras da cidade do Rio de Janeiro, das classes $\mathrm{A}$ e $\mathrm{B}$, e usuárias de smartphones. A entrevista em profundidade com roteiro semiestruturado teve como objetivo entender como estas pessoas se comunicam com as empresas das quais consomem. 
Os entrevistados foram selecionados através de duas etapas. A primeira foi a divulgação de um formulário em uma rede social para que as pessoas pudessem preencher. $O$ formulário consistia em quatro perguntas: possui smartphone, idade, cidade e renda familiar. As pessoas que preencheram e se adequaram ao perfil foram então selecionadas para o estudo.

Os 12 entrevistados escolhidos apresentam idades variadas, ocupações profissionais e estilos de vida diferentes. Criei nomes fictícios para que a identidade dos mesmos fosse preservada.

Abaixo, uma tabela com o nome e perfil dos entrevistados, levando em consideração a idade do mesmo e sua ocupação profissional.

\begin{tabular}{|l|l|l|}
\hline Nome Fictício & Idade & Ocupação Profissional \\
\hline Mariana & 16 anos & Estudante \\
\hline Bruno & 17 anos & Estudante \\
\hline Felipe & 18 anos & Estudante \\
\hline Rafael & 25 anos & Estudante de Administração \\
\hline Carla & 24 anos & Estudante de Direito \\
\hline Juliana & 23 anos & Estudante de Informática \\
\hline Angela & 40 anos & Gerente de Marketing \\
\hline Joana & 36 anos & Coordenadora de Comunicação \\
\hline Daniel & 31 anos & Produtor Cultural \\
\hline Marcia & 55 anos & Empresária \\
\hline Claudia & 54 anos & Diretora de Novos Negócios \\
\hline João & Empresário \\
\hline
\end{tabular}




\subsection{Procedimentos e instrumentos de coleta de dados utilizados no estudo}

A entrevista de pesquisa exploratória foi executada a partir de um roteiro previamente estruturado com 25 perguntas (Anexo 1) separadas em quatro blocos: a) Conhecendo o Consumidor, b) Relação com Empresas, c) Sentimentos, e d) Experiências. A escolha deste modo de coleta se deveu à complexidade do assunto e necessidade de ouvir cada resposta e opinião sobre o tema. Afinal, o objetivo final desta pesquisa é descobrir o porquê da forma como o consumidor se comunica com empresas.

As entrevistas foram realizadas através de 3 meios: telefone, Skype e ao vivo. Todas foram feitas com gravação de voz, autorizada pelo entrevistado, para que depois pudesse ser analisada de modo a extrair todas as informações cedidas, e que podem ter passado despercebidas durante a entrevista.

Escolheu-se horários em que os entrevistados estivessem à vontade para dedicar tempo à exploração dos conceitos. Esta abordagem também permitiu ser didática na compreensão das respostas, pedindo exemplos ou casos para ter certeza do que o entrevistado queria dizer. As entrevistas foram feitas ao longo do mês de maio de 2017.

A abordagem da entrevista foi informal, de modo que o entrevistado ficasse à vontade para responder de forma sincera e contribuir para o estudo. As perguntas, previamente estruturadas, serviram como um apoio para que o entrevistado pudesse falar o quanto quisesse para obter a maior quantidade de informação sobre o tema, porém ocorreram vezes em que o mesmo não mencionou algo relevante à pesquisa. Neste caso, a pergunta foi feita de novo de umaforma que o entrevistado pudesse compreender e respondê-la novamente.

As entrevistas tiveram duração entre 10 a 30 minutos, variando de acordo com o envolvimento do entrevistado com o assunto abordado e o entendimento da pergunta. Ocasiões em que o entrevistado não entendia o conteúdo da pergunta, o mesmo era explicado de outra forma e exemplificado, para melhor entendimento. No Anexo I encontra-se o roteiro utilizado nas entrevistas. 


\subsection{Formas de tratamento e análise dos dados coletados para o estudo}

A análise de conteúdo trabalha com materiais textuais escritos. Existem dois tipos de textos: os que são construídos no processo de pesquisa, por exemplo, transcrições de entrevistas e observações; e textos que já foram produzidos para outra finalidade, por exemplo, jornais e memorandos (Bauer e Gaskell, 2002). No caso deste estudo, o texto foi o produzido durante a pesquisa com as transcrições das entrevistas.

"Esta análise é considerada uma técnica para tratamento de dados que visa identificar o que está sendo dito a respeito de determinado tema. " (Vergara, 2005 , p. 15). Desta forma, podemos analisar o que foi dito e fazer observações do que está por trás do texto.

A análise de conteúdo pode ser explicada como:

“(...) um conjunto de técnicas de análise das comunicações visando obter, através de procedimentos sistemáticos e objetivos de descrição do conteúdo das mensagens (quantitativos ou não) que permitam a inferência de conhecimentos relativos às condições de produção/recepção (variáveis inferidas) destas mensagens. " (Bardin, 1977, p.42)

"A finalidade da análise de conteúdo é produzir inferência, trabalhando com vestígios e índices postos em evidência por procedimentos mais ou menos complexos" (Puglisi; Franco, 2005).

Pensando nisso, optou-se por organizar as etapas do tratamento em três fases. De acordo com Bardin (2006), estas fases são: 1) pré-análise, 2) exploração do material e 3) tratamento dos resultados, inferência e interpretação.

A primeira fase é a pré-análise, onde se organiza o material a ser analisado com o objetivo de torná-lo operacional, sistematizando as ideias iniciais. Nesta fase, houve a transcrição das entrevistas em forma de perguntaresposta a partir da gravação dos áudios das mesmas.

Em seguida, a codificação das informações extraídas da transcrição é feita. Desta forma, há uma compilação de dados para que o conteúdo analisado fique em destaque. Criou-se um modelo onde as respostas de todos os entrevistados estivessem organizadas por tópico e insights semelhantes. 
A terceira fase diz respeito ao tratamento dos resultados, inferência e interpretação. Esta etapa é destinada ao tratamento dos resultados, onde há o momento de inferência e análise crítica. Nesse estudo, a etapa é o capítulo 4, onde são apresentados e analisados os dados coletados durante a pesquisa.

\subsection{Limitações do Estudo}

$\mathrm{Na}$ etapa da pesquisa exploratória-qualitativa, uma limitação está relacionada à quantidade de entrevistas feitas. Se fosse possível realizar uma pesquisa com uma maior quantidade de entrevistados, os resultados poderiam ter sido mais enriquecedores. Entretanto, com as pesquisas realizadas, pode-se perceber a profundidade das respostas. Com o número baixo de entrevistas é possível que o estudo não seja considerado válido, por isso recomendaria fazer uma pesquisa quantitativa com uma amostra representativa para concluir os dados.

Outra limitação seria a possível tendenciosidade dos entrevistados. As entrevistas foram feitas de modo que não levasse a interpretações erradas ou induções de respostas. Porém, esta limitação foi amenizada ao passo que as perguntas foram feitas de maneira ampla, apenas fornecendo explicações quando os entrevistados pediam.

Algo que também poderia ser considerado uma limitação é a visão focada da pesquisa apenas no consumidor. Seria interessante poder entrevistar empresas com o objetivo de verificar as formas como se comunicam com os consumidores e entender porque se comunicam desta forma. Outra alternativa seria mostrar para estas empresas os resultados desta pesquisa para que possam melhorar sua comunicação com o consumidor e iniciar uma discussão de como fazer esta tarefa. Entretanto, isto não foi incluído pelo tempo que tivemos para concluir o trabalho. 


\section{Apresentação e análise dos resultados}

\subsection{Unanimidade em relação à preferência por serviços de mensagem para comunicação com empresas}

No universo pesquisado - restrito a cidade do Rio de Janeiro - nota-se claramente a preferência por canais digitais no relacionamento com as empresas. Como todos os entrevistados tinham alto poder aquisitivo e nível sócio cultural, o que os une parece ser a intimidade com o meio digital e a disponibilidade para a interação, que geram um hábito, ou mais destreza. $\mathrm{E}$ assim, estimulam que o indivíduo vá além na navegação. Os entrevistados utilizam para justificar sua escolha diferentes argumentos, mas basicamente estão falando de eficiência, segurança e agilidade.

"Whatsapp, porque é muito mais rápido do que email e menos incômodo e invasivo do que ligação. "

Daniel, 31 anos

"Se você usa um canal online normalmente não tem erro de compreensão e as coisas acontecem mais rápido, não perco tempo explicando..."

Marcia, 55 anos

"Eu não interajo com ninguém nunca! Já escolhi um médico só porque ele marcava consulta pelo WhatsApp, tudo que tem possibilidade de marcar pelo Facebook ou WhatsApp, eu prefiro. É e-mail, chat online... agora ligação pra mim é não ter outro jeito mesmo. "

Joana, 36 anos

Esta unanimidade dos entrevistados em relação à preferência por ter a opção de compra ou atendimento online sempre se repete em todas as idades e não se diferencia em gênero. Tanto os "nativos digitais", quanto os "imigrantes digitais", acabaram por ter preferências em interações com empresas muito 
semelhantes, mesmo que a agilidade ou destreza com que estabeleçam essas relações sejam diferentes.

Evidencia, também, a penetração da cibercultura na sociedade e como ela está já entranhada: já não existe no grupo pesquisado quem não participe desta cultura. Outra observação importante que podemos tirar dessa unanimidade é a verificação da abrangência da convergência/divergência digital, ou seja, todos estão utilizando o mesmo meio, internet, através de diferentes formas físicas, celular/computador/tablet, e em aplicativos diversos como WhatsApp, Messenger, Skype e aplicativos de Chats.

"Online, não tenho a menor dúvida! Por acaso meu cabeleireiro e minha manicure eu marco por WhatsApp, hoje o salão não me dá um telefone no WhatsApp, mas se tivesse eu usava também! "

Angela, 40 anos

"Preferiria usar o WhatsApp, mas quando tem aquele sistema de conversa, tipo um chat online, por dentro do site que nem a Ebay tem, eu prefiro. "

Julia, 23 anos

"Normalmente não preciso me comunicar, mas se tiver que é email ou WhatsApp, telefone nunca!"

Marcia, 55 anos

\subsection{Preferências entre serviços de mensagens síncronos ou assíncronos em função do tipo de comunicação com as empresas}

Em seguida, percebeu-se a diferença entre serviços de mensagens síncronos e assíncronos. Online é fundamental, como já vimos, mas todos os entrevistados definem canais síncronos também como essenciais na solução de problemas mais imediatos, questões que demandem soluções rápidas. Exemplos são dúvidas, pós-venda, reclamações, alteração de um pedido e outros mais relacionados à prestação do serviço, não à venda, ao pedido. 
"O ideal realmente, neste caso, seria algum tipo de ferramenta online que me respondam rápido, onde eu posso falar o problema e eles, pelo menos, possam me dar uma estimativa de tempo de solução na hora. "

Rafael, 25 anos

E como relacionar as preferências dentre tantos canais? A análise das entrevistas mostra que as escolhas se referem a situações ou momentos. Alguns exemplos que elucidam estas preferências:

Quando a empresa vai em busca do consumidor, este prefere que a comunicação seja assíncrona. Desta forma, o consumidor não sente, na sua vida corrida, que a empresa o está incomodando, invadindo ou o interrompendo. As mensagens que chegam por email ou SMS não são problemáticas, pois o consumidor tem a possibilidade de ler estas mensagens na hora em que pode e quer, e não na hora que a empresa enviou. O telemarketing é muito citado como um canal síncrono em sua pior forma, um meio de invasão da privacidade.

"Detesto telemarketing, não suporto, mas gosto da comunicação via email, porque você vê na hora que você quer."

Angela, 40 anos

"Odeio quando toca o telefone e é aquela voz automatizada da Oi falando assim 'aproveita essa promoção! '”

Carla, 24 anos

"(Falando sobre ofertas e promoções) preferia que fosse no email, assim não me interrompe no dia-a-dia! "

Claudia, 54 anos

Quando existe um contato prévio e o cliente espera uma resposta no médio prazo e a empresa escolhe o email ou SMS, não existe problema, pois o consumidor tem a possibilidade de ler estas mensagens na hora em que pode e quer, e não na hora que a empresa enviou.

"Geralmente não quero falar no telefone, prefiro email, algum texto que eu respondo que eu não precise responder naquela hora. "

Daniel, 31 anos 
No entanto, se o interesse na comunicação com a empresa partir do consumidor - seja reclamação, dúvida, pedir orçamento etc. - e este precisa de solução eficiente e imediata, a preferência é por canais que ativem sinais, como SMS, chats online ou WhatsApp, e não o email. Neste sentido, a comunicação síncrona ganha peso e relevância, pois se relaciona à agilidade no atendimento.

\subsection{Vantagens percebidas no agendamento de serviços via internet}

Outro ponto marcante em que a universalidade da cibercultura e da convergência digital se mostram como explicação é a consistência com que as vantagens do agendamento online foram percebidas pelos consumidores das diversas faixas etárias.

Duas vantagens foram bastante citadas. A primeira seria a confirmação do agendamento de serviços através de email ou SMS, que funcionam como uma garantia deste agendamento, e a segunda seria a praticidade de escolher um horário visualizando um calendário.

"Quando eu marco online ao invés de uma ligação eu me sinto mais marcada do que o outro, porque vem um email confirmando, tem várias coisas. E marcar online também é possível ver o agendamento visualmente, que fica bem mais fácil de decidir."

Claudia, 54 anos

"Acho que seria legal se pudesse ir no site, tipo no do dermatologista, e tivesse como ver todos os horários e você pudesse marcar por lá, ficaria mais fácil. "

Mariana, 16 anos

“Já liguei pro restaurante e o cara esqueceu meu pedido, no iFood eu tenho a comprovação de que o cara já catou o pedido e eu sei que tá vindo. No aplicativo eu sei que tá salvo, então não tem erro."

Rafael, 25 anos 
"(Sobre pedir comida na internet) aí não preciso falar, não anotou errado, meu pedido tá alí no sistema e tenho mais confiança até. "

Daniel, 31 anos

Ou seja, para os entrevistados, o fato de ter seu pedido salvo e confirmado via internet, (através de SMS, email, WhatsApp etc.) tem como principal valor mais confiança e segurança de que seu pedido e o seu conteúdo será exatamente conforme solicitado.

\subsection{Acreditam que a comunicação telefônica é falha}

Essa decepção também acontece no uso de telefone, percebido como o canal essencialmente síncrono, porém com inúmeras ressalvas referentes seja à tecnologia ou ao nível de serviço oferecido. Detalhando, comentam a infraestrutura precária no país, ocasionando a queda frequente de ligações, a falta de preparo e/ou treinamento dos atendentes para entender problemas e as URAs com seus menus intermináveis ou que não chegam nunca ao problema informado.

"Quando a internet não tava funcionando eu tive que ligar pra provedora e perguntar várias vezes o que estava acontecendo, aí me transferiram pra um lugar, aí depois outro, depois outro. Liguei várias vezes, foi muito chato!"

Bruno, 17 anos

"Todos costumam ser ruins (canal de atendimento por telefone), porque você tem que andar por múltiplos níveis de opções até você conseguir falar com alguém, e as ligações caem sempre! Tão jogando todo o trabalho da comunicação pra cima do consumidor. "

João, 61 anos

Dentro da noção de eficiência se inclui evitar qualquer tipo de retrabalho, ou seja, ter que fazer uma tarefa várias vezes até que ela dê certo. Neste momento, o online se contrapõe ao telefone, mas isso não acontece sempre em todas as situações. 
"Telefone, por exemplo quando ligo pra um restaurante, é sempre dramático, porque atende uma copeira, que muitas vezes não tem interesse, então qualquer coisa que você pergunta a pessoa tá despreparada para responder, acaba demorando muito e muitas vezes vem errado! "

Marcia, 55 anos

\subsection{Acreditam na necessidade de um canal telefônico para solução mais imediata de problemas com empresas}

Numa emergência, é essencial o canal verdadeiramente síncrono, como o chat, o telefone, o WhatsApp. Desde que ele não seja apenas anunciado como síncrono e funcione verdadeiramente a todo tempo. Exemplos são os telefones 24 horas, o chat online, a mensagem respondida de imediato. Algumas pessoas ressaltam que, neste caso, as URAs (Unidade de Resposta Audível) e os atendentes mal treinados atrapalham em muito a eficiência do atendimento.

"É importante, precisa ter, mas são ruins, porque você tem que andar por múltiplos níveis de opções até você conseguir falar com alguém, e as ligações caem sempre! Tão jogando todo o trabalho da comunicação pra cima do consumidor."

João, 61 anos

"Não acho legal você explicar sua situação e o cara te encaminhar pro mesmo canal. Muitas vezes, você cai no canal, e o cara não entendeu do que se trata e você já explicou isso, eu acho que a comunicação é falha(...)"

Rafael, 25 anos

Apesar da comunicação telefônica ser considerada falha pelos consumidores, os mesmos a consideram uma necessidade que não pode ser substituída e nem desaparecer. Neste caso específico, percebemos que uma pequena diferença entre os nativos e imigrantes digitais. Ambos preferem a utilização de serviços via internet e utilizariam telefones em caso de emergência. Apenas para os mais velhos do grupo, usar o telefone é mais uma questão de imediatismo do que emergência. 
"Matar o canal de telefone eu acho ruim. Ajudei meu pai no aplicativo do Uber, busquei o telefone e não achei, aí achei um canto pra fazer reclamação e descrevi, mas ninguém me dava retorno! Foi a pior experiência online, nem uso mais Uber agora. Ele (pai) teve que ir lá na empresa pra resolver."

Angela, 40 anos

“(..) odeio as empresas excessivamente digitais, por exemplo, a ingresso.com, que quando você quer falar, ou reclamar de alguma coisa, ou o próprio Uber, é dificílimo! Acho isso horrível. "

Marcia, 55 anos

"Quando caiu a internet não teve jeito, tive que ligar!"

Bruno, 18 anos

" (Falando sobre uso do telefone) se eu tô querendo uma informação específica que não está no site, ou se estou querendo fazer uma reclamação, ou se tô querendo tratar de alguma situação excepcional, eu prefiro ter acesso a uma pessoa de uma forma fácil. "

João, 61 anos

"A Amazon não fica no Brasil então fiz tudo via site, reclamei do pedido, fiz a troca, foi bom, mas quando você se irrita com alguma coisa, tipo a ingresso.com, que não tem o outro canal que é o telefone, acho que isso devia ser proibido na lei! "

Claudia, 54 anos

\subsection{Acreditam que a comunicação com empresas por e-mail não seja imediata ou garantida o suficiente}

Chamou atenção nas entrevistas a imagem do email junto aos entrevistados, que espontaneamente destacavam esta ferramenta - dentre as online - como menos eficiente no relacionamento com empresas. Os consumidores acreditam que o email seja uma ferramenta assíncrona válida 
para quando a empresa entrar em contato, pois não interrompe. Porém, quando o consumidor está entrando em contato com a empresa, espera-se uma resposta imediata, ou, síncrona, o que não acontece na maioria das vezes.

Apesar de preferirem se comunicar via internet, o email aparece como uma forma menos preferida já que, além da eventual resposta poder demorar dias, nenhuma garantia de resposta é percebida entre os entrevistados.

"Outra coisa que eu acho ruim é empresa que no site tem um email, mas eles levam 3-4 dias pra responder aquele email, como se isso fosse possível! "

Marcia, 55 anos

Eu ligo, é mais fácil porque não respondem nunca (o email), ou usaria chat online se tivesse e funcionasse."

Carla, 24 anos

"Com email você nem sempre tem uma resposta muito imediata, você manda e torce pra alguma hora alguém fazer alguma coisa. "

João, 61 anos

"Mandei email e ninguém me respondia, até eu botar no Facebook. "

Daniel, 31 anos 


\section{Conclusões, Sugestões e Recomendações}

O objetivo do estudo é entender a mudança de comportamento do consumidor na sua interação com empresas, levando em consideração dois tipos principais de interação: agendar um serviço/comprar um produto ou reclamar/resolver problemas com uma empresa. Após análise teórica e baseados nas entrevistas qualitativas, os resultados se mostraram bastante profundos e levaram a conclusões, algumas vezes, inesperadas. Estas conclusões e recomendações são, como um todo, válidas, mas dependendo de porte, geografia, ambiente de negócios ou perfil de clientes, cada um dos pontos será mais ou menos relevante para uma empresa.

Vale aqui uma ressalva, com base nas entrevistas realizadas, e que pontua os relacionamentos entre consumidores e empresas na cibercultura. Se vender é o movimento mais visível e concreto, este ato, num meio lotado de redes sociais, conversas e reviews, é apenas um dos elementos deste relacionamento. Explicações sobre o produto, conteúdo informativo, atendimento de pós-venda, investigação, informação e conversa é que delimitam um relacionamento consistente.

Neste sentido, a comunicação consumidor-empresa se dá, não mais através de informações pontuais, mas de relacionamentos em rede no ciberespaço. Logo, é imperioso produzir conteúdos de qualidade nos diferentes meios (e adequados a cada um deles), gerando mais indicações nas mídias sociais e aparecendo entre as primeiras posições no Google, pois é assim que o potencial cliente vai encontrar a empresa quando quiser mais informações sobre o produto ou serviço. Além deste conteúdo, é necessário construir atributos de marca sólidos e consistentes.

Fica claro que, na cibercultura, para melhor atender seus consumidores, as empresas devem ampliar canais e se adequar a cada perfil de público, ou momento na cadeia de consumo. É importante entender que em alguns momentos é essencial o canal síncrono, de resposta rápida e que soluciona problemas, e que em outros um canal assíncrono pode atender bem. Quando consumidores tomam a iniciativa de uma interação com empresas, estes preferem utilizar um serviço de mensagens síncrono, tipo WhatsApp ou um chat online. Já quando a 
iniciativa da interação parte de uma empresa, a preferência é que esta comunicação seja assíncrona, considerada não invasiva.

Abrir diferentes canais de interação é essencial, pois um site não elimina um aplicativo que por sua vez não substitui uma página do Facebook. Telefone, email, WhatsApp, chats, e outros aplicativos, são todos canais necessários, pois são usados dependendo do momento da comunicação consumidor-empresa. A empresa deve se comprometer e estar presente em todos estes canais, e isto demonstra, de novo, a convergência/divergência digital.

O conceito de "nativos digitais" e "imigrantes digitais" deve ser olhado como um conjunto de atores que interagem, e não como universos distantes um do outro, no que se refere à presença de empresas e consumidores no ciberespaço. Os "nativos digitais" são grandes professores e estimuladores da adoção de novos hábitos, e num futuro próximo serão também potenciais clientes.

Inicialmente, acredita-se que a idade do consumidor seria um fator diferencial nas respostas dos entrevistados, o que não foi corroborado pelas entrevistas. Entretanto, um dos problemas percebidos durante a pesquisa é que estes jovens, "nativos digitais", entrevistados ainda não estão numa fase adulta 0 suficiente para que tenham necessidades frequentes de comunicação com empresas. Este fato pode ter contribuído para não termos ainda como perceber idade como um fator diferencial. Só teremos como reavaliar esta questão em alguns anos.

As entrevistas mostram que consumidores na cibercultura são essencialmente indivíduos com as necessidades básicas humanas de pertencimento, querem ser bem atendidas em suas especificidades. Para eles, não existe mais distinção entre online e off-line, existem momentos e demandas que devem ser atendidas por diferentes canais, sem que o consumidor enumere se são na web ou físicos. O que ele prefere é ser atendido de forma rápida, eficiente e ver suas questões resolvidas.

Por último, desenvolver o trabalho, mergulhando nos conceitos trazidos por autores de diversos saberes e conversar com pessoas nas entrevistas, foi fundamental para entender que viver no ciberespaço é imperativo para as empresas. A cibercultura determina novos jeitos de interagir com impacto - e também reforço - de padrões culturais.

Acredita-se que o estudo atingiu seu objetivo ao poder entender e explicitar preferências na forma como consumidores desejam se comunicar com empresas, inclusive deixando clara a característica de que, pelo menos por 
enquanto, nativos e imigrantes digitais se comportam de maneira extremamente semelhante, todos participando de uma mesma cibercultura e utilizando a mesma convergência/divergência digital de meios e ferramentas para se comunicar com empresas.

Como desdobramentos futuros, essa linha de estudo pode ser desenvolvida através de uma pesquisa quantitativa para validar os resultados encontrados, porém com uma amostra maior.

Acredito que, por causa das razões citadas no item anterior, não poderemos repetir esta análise por alguns anos. Desta forma poderemos esperar os chamados nativos digitais estarem um pouco mais velhos para se envolverem mais com interações com empresas.

Algo interessante que também poderia ser feito em uma pesquisa futura seria entrevistar empresas com o objetivo de verificar as formas como se comunicam com os consumidores e entender porque se comunicam desta forma. Outra alternativa seria mostrar para estas empresas os resultados desta pesquisa para que possam melhorar sua comunicação com o consumidor e iniciar uma discussão de como fazer esta tarefa. Entretanto, isto não foi incluído pelo tempo que tivemos para concluir o trabalho.

A partir desta pesquisa futura, acredita-se poder validar a pesquisa qualitativa feita neste estudo. E, a partir disto, as empresas poderão ter uma visão melhor da preferência dos consumidores para a forma de comunicação. 


\section{Referências Bibliográficas}

ADLER, Ronald B., \& ELMHORST, Jeanne. M. Communicating at work: principles and practices for business and the professions. 10 $0^{\mathrm{a}}$ ed. Boston: McGraw-Hill, 2010.

BARDIN, Laurence. Análise de conteúdo. Lisboa: Edições 70, 1977.

BAUER, Martin W.; GASKELL, George. Pesquisa qualitativa com texto: imagem e som : um manual prático. Tradução de Pedrinho A. Guareschi. Petrópolis, RJ : Vozes, 2002.

CASTELLS, Manuel. A sociedade em rede. São Paulo: Paz e Terra, 1999.

CASTELLS, Manuel. A galáxia da internet. Rio de Janeiro: Jorge Zahar, 2003.

DAMATTA, Roberto. Carnavais, malandros e heróis: para uma sociologia do dilema brasileiro. 6.ed. Rio de Janeiro: Rocco, 1997.

DAMATTA, Roberto. A Casa \& A Rua: espaço, cidadania, mulher e morte no Brasil. 5.ed. Rio de Janeiro: Rocco, 1997.

ESCOBAR, Arturo. Welcome to Cyberia, notes on the Anthropology of Ciberculture. en The Cybercultures Reader, Bell, David, Kennedy, Barbara, eds. NY \& London: Routledge, 2000.

JENKINS, Henry. Cultura da convergência. 2. ed. São Paulo: Aleph, 2009.

LÉVY, Pierre. Cibercultura. São Paulo: Ed. 34, 1999.

MILLER, Daniel; SLATER, Don. The Internet, an Ethnographic Approach. Oxford: Berg, 2000. 
NAVARRO, Victória. Conectar físico e digital é mais importante que nunca. 2017. Disponível em < http://www.meioemensagem.com.br/home/midia/2017/05/31/conectar-fisico-edigital-e-mais-importante-que-nunca.html> Acesso em 31 de maio de 2017.

PAIVA, Fernando. Mensageria no Brasil. Panorama Mobile Time/Opinion Box, fevereiro de 2017. Disponível em <http//www.panoramamobiletime.com.br> Acesso em 16 de maio de 2017.

POOL, Ithiel de Sola. Technologies of Freedom: On Free Speech in an Electronic Age. Cambridge, Massachusetts: Harvard University Press, 1983.

PORTER, David. Internet Culture. NY \& London: Routledge, 1996.

PRENSKY, Marc. Digital Natives, Digital Immigrants. On The Horizon, MCB University Press, Vol. 9, No. 5, 2001.

PUGLISI, M.L.; FRANCO, B. Análise de conteúdo. 2. ed. Brasília: Líber Livro, 2005.

REID, E.M. Cultural formations in text-based virtual realities. M.A. Thesis, University of Melbourne, $1994 . \quad$ Disponível em <http://www.ee.mu.oz.au/papers/emr/work.html> Acesso em 10 de maio 2017.

SILVA, Lídia J. O. L. A Internet - a geração de um novo espaço antropológico. In: LEMOS, André; PALACIOS, Marcos. Janelas do Ciberespaço Comunicação e Cibercutura. 2. ed. Porto Alegre: Sulina, 2004. p. 151 - 171. Disponível em <http://bocc.unisinos.br/pag/silva-lidia-oliveira-Internet-espacoantropologico.pdf>. Acesso em 2 de maio de 2017.

SOZIO, Maria Eugenia et al. Children and Internet use: A comparative analysis of Brazil and seven European countries. 2015. Disponível em <http://cetic.br/media/docs/publicacoes/5/Children\%20and\%20Internet\%20use.p df> Acesso em 27 de maio de 2017.

VERGARA, Sylvia Constant. Métodos de pesquisa em administração. São Paulo: Atlas, 2005. 


\section{Anexo 1 - Roteiro Semi-Estruturado das Entrevistas}

Conhecendo o Consumidor

1. Com que frequência você fica na internet/usa o celular online?

2. O que costuma fazer online?

a. Sozinho (por exemplo, google, youtube, facebook)

b. Com amigos (jogos, youtube, etc.)

3. O que te estimula a entrar online (especificamente no celular: jogos, amigos, notícias etc.)?

4. Como você pessoalmente se comunica com seus amigos? Porque?

5. O que falta, para você, no ambiente online?

a. Por que?

6. Qual forma ou meio você mais utiliza para se comunicar com amigos (numa situação ideal)?

Relação com Empresas

7. Com que frequência você interage (serviço, compra, pede informações) com empresas?

8. Qual sua maior forma de comunicação?

a. Entre amigos/familiares

b. Com empresas

9. Como você faria se quisesse:

a. Informações sobre uma empresa ou de seus serviços/produtos

b. Comprar/marcar (serviço de unha, restaurante etc.)

c. Avaliar/Reclamar (expressam suas opiniões)

10. Como você prefere se comunicar com empresas (numa situação ideal)?

11. Sugestões para melhorar comunicação empresa x consumidor.

Sentimentos 
12. (Para os imigrantes digitais) desde a existência dos smartphones, você mudou o jeito que age ou pensa, como se comporta?

13. Para você, existe alguma diferença entre marcar um serviço, ou até comprar, utilizando internet ao invés de ligação?

14. Como se sente utilizando smartphones para fazer o que quiser?

15. Você utiliza telefone fixo? Como se sente quando precisa ligar para alguém?

16. Como se sente quando alguém te liga?

a. Empresa

b. Amigos/Familiares (conversa é rápida?)

17. Você sente algum medo, ou alguma fobia, quando está online?

18. Você sente algum medo, ou alguma fobia, quando te ligam?

a. E quando você tem que ligar para alguém porque não tem outro jeito?

19. Alguma coisa na internet te dá um desconforto?

a. E usando o celular para fazer ligações ou recebê-las?

\section{Experiências}

20. Faça uma lista das coisas que você mais usa no smartphone. (Exemplo: facebook, instagram, phone, calendar, notes etc.)

21. Classifique eles na ordem de importância para você no dia-a-dia.

22. No geral, qual a sua forma de comunicação preferida? (Confrontar com o oposto, tel. ou internet)

23. Pode me descrever situações boas e/ou ruins com os meios de comunicação?

24. Se tivesse a opção de marcar o serviço de unha ou reserva uma mesa de um restaurante através de um ambiente online, você ligaria ou pediria via online?

25. Imagine a seguinte situação: Você está em casa com seus amigos assistindo a um filme, ou a estreia de Game of Thrones, e decidem pedir uma pizza. O que vocês fazem? Alguém se voluntaria para ligar? Há alguma discussão ou impedimento? Pedem pelo site/aplicativo? 


\section{Anexo 2 - Quadro de Meios de Comunicação}

\section{Algumas considerações ao escolher um canal de comunicação}

\begin{tabular}{|l|l|l|l|l|l|l|}
\hline & Riqueza & Velocidade & $\begin{array}{l}\text { Controle da } \\
\text { mensagem }\end{array}$ & $\begin{array}{l}\text { Controle da } \\
\text { atenção }\end{array}$ & Tom & $\begin{array}{l}\text { Nivel de } \\
\text { detalhe }\end{array}$ \\
\hline Face a face & Alto & Síncrono & Baixo & Alto & Pessoal & Moderado \\
\hline Telefone & Moderado & Síncrono & Baixo & Moderado & Pessoal & Moderado \\
\hline Mensagem & Moderado & Assíncrono & Moderado & Baixo & Moderado & Baixo \\
\hline de voz & & & & & &
\end{tabular}

\section{Algumas considerações ao escolher um canal de comunicação}

\begin{tabular}{|l|l|l|l|l|l|l|}
\hline & Riqueza & Velocidade & $\begin{array}{l}\text { Controle da } \\
\text { mensagem }\end{array}$ & $\begin{array}{l}\text { Controle da } \\
\text { atenção }\end{array}$ & Tom & $\begin{array}{l}\text { Nível de } \\
\text { detalhe }\end{array}$ \\
\hline E-mail & Baixo & Assíncrono & Alto & Baixo & $\begin{array}{l}\text { Impessoal- } \\
\text { Moderado }\end{array}$ & Alto \\
\hline Chat & Baixo & $\begin{array}{l}\text { Assíncrono } \\
\text { (++ rápido) }\end{array}$ & Moderado & Moderado & Moderado & Baixo \\
\hline Mensagem & Baixo & $\begin{array}{l}\text { Assincrono } \\
\text { (+ rápido) }\end{array}$ & Alto & Baixo & $\begin{array}{l}\text { Impessoal- } \\
\text { Moderado }\end{array}$ & Baixo \\
\hline Impresso & Baixo & Assíncrono & Alto & Baixo & $\begin{array}{l}\text { Mepende do } \\
\text { estilo do escritor }\end{array}$ & Alto \\
\hline
\end{tabular}

Fonte: Adler \& Elmhorst (2010) 